\title{
EROSÃO DO SOLO NA AMAZÔNIA: ESTUDO DE CASO NA REGIÃO DO APIAÚ, RORAIMA, BRASIL
}

\author{
Reinaldo Imbrozio BARBOSA ${ }^{1}$, Philip Martin FEARNSIDE ${ }^{2}$
}

Resumo - O estudo analisou a erosão do solo pela ação da água das chuvas, em dois usos da terra (floresta primária e pastagem derivada de floresta) entre agosto de 1988 e fevereiro de 1992 , na região do Apiaú, Estado de Roraima, Amazônia brasileira. Para um declive padrão de $20 \%$, os resultados indicaram que a erosão em um sistema de pastagem com Brachiaria humidicola $\left(1.128 \mathrm{~kg} \cdot \mathrm{ha}^{-1} \cdot\right.$ ano $\left.^{-1}\right)$ foi 7,5 vezes maior quando comparado com os dados obtidos para floresta primária (150 kg.ha- . ano $^{-1}$ ) no mesmo periodo. O escoamento superficial ("runoff") foi de 3,18 x $10^{6}$ l.ha ${ }^{-1}$.ano $0^{-1}$ para o pasto e de $1,13 \times 10^{6} \mathrm{I}_{\mathrm{ha}} \mathrm{h}^{-1}$. $\mathrm{ano}^{-1}$ para a floresta primária. Embora situados a menos de $1 \mathrm{~km}$ de distância, a precipitação pluviométrica anual que efetivamente atingiu o solo nos dois sistemas foi desigual $\left(P<0,001 ; t_{0.05,1,36}\right)$ e refletiu a diferença de cobertura vegetal entre a floresta $(1.538 \mathrm{~mm})$ e a pastagem $(2.109 \mathrm{~mm})$. Os resultados indicam que a substituição de florestas tropicais por pastagens na Amazônia aumenta a erosão laminar e seus efeitos podem ser refletidos na sócio-economia regional e global.

Palavras-chave: erosão, escoamento superficial, pastagem, Roraima, solo

\section{Soil Erosion in Amazonia: A Case Study in the Apiaú Region, Roraima, Brazil}

\begin{abstract}
The study analyzed soil erosion by rain water in two land uses (primary forest and pasture derived from forest) from August 1988 to February 1992, in the Apiaú region, Roraima State, Brazilian Amazonia. For a standard slope of $20 \%$, the results indicated that soil erosion in Brachiaria humidicola pasture $\left(1,128 \mathrm{~kg} \cdot \mathrm{ha}^{-1} \cdot \mathrm{y}^{-1}\right)$ was 7.5 times higher than that under primary forest $\left(150 \mathrm{~kg} \cdot \mathrm{ha}^{-1} \cdot \mathrm{y}^{-1}\right)$ in the same period. The runoff was $3.18 \times 10^{6} \mathrm{l} \cdot \mathrm{ha}^{-1} \cdot \mathrm{y}^{-1}$ in the pasture and $1.13 \times 10^{6} 1 . \mathrm{ha}^{-1} \cdot \mathrm{y}^{-1}$ in the primary forest. Although located less than $1 \mathrm{~km}$ apart, the rain that reached the soil annually in the two systems was unequal $\left(\mathrm{P}<0.001 ; \mathrm{t}_{0.05 .1 .36}\right)$, reflecting the difference in cover between forest $(1,538 \mathrm{~mm})$ and pasture $(2,109 \mathrm{~mm})$. The results suggest that substitution of tropical forests by pastures in Amazonia increases soil erosion, and that the effects could be reflected in the regional and global social-economy.
\end{abstract}

Key-words: erosion, pasture, Roraima, runoff, soil

\section{INTRODUÇÃO}

Erosão do solo na Amazônia brasileira esta ligada diretamente a questões sócio-econômicas e ambientais que podem afetar não só a manutenção da fertilidade do solo em sistemas agropastoris, como também a longevidade de sistemas hidrelétricos e o transporte de carbono para reservatórios globais marinhos
(Fearnside et al., 1986; Forsberg et al., 1989). Em geral, erosão vem sendo omitida das discussões sobre os modelos de desenvolvimento regional, quase que exclusivamente pela completa falta de dados que quantifiquem e/ou permitam uma análise planejada do uso da terra na Amazônia (ver Lal, 1977).

Em Roraima, um dos estados amazônicos criados pela Constituição

1. Instituto Nacional de Pesquisas da Amazônia/CPEC CTA-INPA/GERR, C.P. 96, 69301-970 Boa Vista/Roraima/BRASIL, Fone/fax: 0xx-95-623 9433, imbrozio@technet.com.br

2. Instituto Nacional de Pesquisas da Amazônia/CPEC, C.P. $47869011-970$ Manaus/Amazonas/ BRASIL, Fone: 0xx-92-643 1822, pmfearn@inpa.gov.br 
de 1988, a oferta de terra ainda é alta devido à pressão fundiária que foi estabelecida pela política regional de incentivo à migração como forma de acelerar o desenvolvimento local (Silveira \& Gatti, 1988; Barbosa, 1993; Mougeot \& Léna, 1994). Este ingrediente resultou em um aumento de mais de 57 vezes no total de áreas desmatadas entre $1978\left(100 \mathrm{~km}^{2}\right)$ e $1998\left(5.791 \mathrm{~km}^{2}\right)$ em todo o estado (INPE, 2000). Do total alterado, cerca de $51-54 \%$ são pastagens produtivas ou degradadas (Barbosa \& Fearnside, 1999). Este cenário faz de Roraima um exemplo da velocidade com que áreas de florestas primárias na Amazônia estão sendo rapidamente transformadas em outros usos da terra. Estes, de modo geral, propiciam o aumento da taxa de erosão causando danos aos agrossistemas pela queda na produtividade (Brown \& Wolf, 1984; Pimentel et al., 1995) e pela exportação de estoques de carbono contidos na matéria orgânica do solo (Braun, 1962; Myers, 1988; Fearnside \& Barbosa, 1998). Ambos os casos afetam diretamente a capacidade de suporte humano e levam ao rápido esgotamento do poder de investimento no setor público devido a velocidade com que novas áreas de florestas são abertas para a produção.

Tentando entender parte deste processo estabelecido na Amazônia, nós objetivamos quantificar a erosão do solo pela ação da água da chuva em dois tipos de uso da terra em Roraima: floresta primária (natural) e pastagem derivada de floresta (maior agroecossistema da região). Este procedimento visou demonstrar as diferenças existentes entre os dois sistemas quanto às perdas de solo (sedimento + material presente na suspensão), ao longo das diferentes fases climáticas anuais da região (seca e chuva). Este estudo faz parte do projeto "Erosão do Solo na Amazônia Brasileira" (Fearnside et al., 1986), sendo o complemento do trabalho iniciado por Barbosa (1991) na vertente de Roraima.

\section{ÁREA DE ESTUdO}

A área de estudo foi centrada na Vila do Apiaú $\left(02^{\circ} 33^{\prime} 11^{\prime \prime} \mathrm{N}\right.$ e $61^{\circ} 18^{\prime}$ 27" W), uma colônia agrícola implantada entre 1980/81 e localizada no município de Mucajai, Roraima, extremo norte da Amazônia brasileira (Figura 1). Esta região é caracterizada por grandes extensões de terra com pastagens convertidas de florestas e, pelo elevado fluxo de migrantes que aceleram o processo de desmatamento. A vegetação original da área foi caracterizada pelo Projeto RADAMBRASIL (Brasil, 1975) como um mosaico entre dois tipos de Floresta Tropical Densa: submontana em relevo dissecado (Fdn) e (b) sob baixas cadeias de montanhas $(\mathrm{Fdt})$. Este último distribuido principalmente entre as serras e serrotas locais.

A altitude nos locais de montagem do experimento variou de 100m a 180m (Barbosa \& Fearnside, 

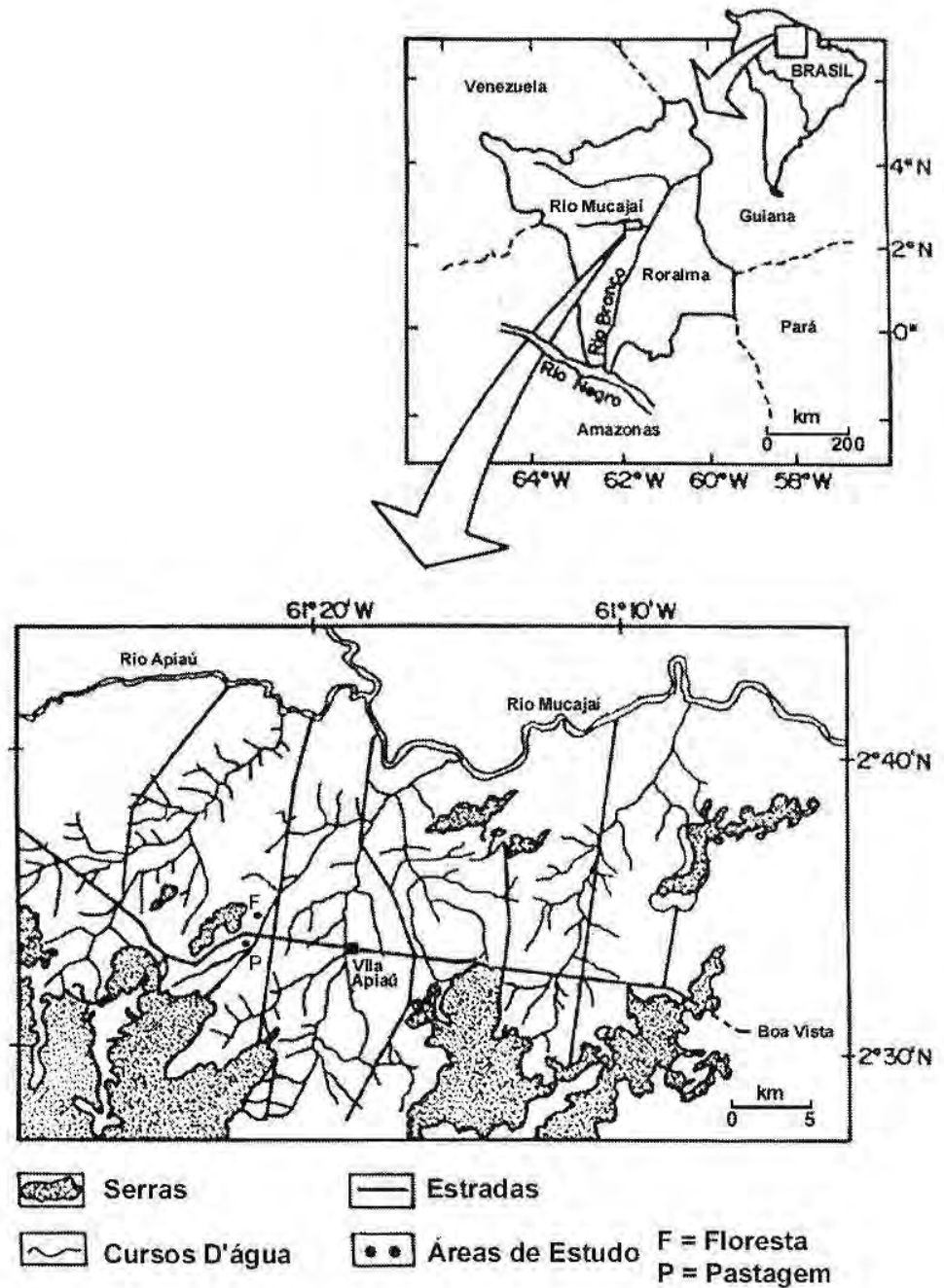

Figura 1. Localização da área de estudo.

1996a). O clima da região é do tipo "Ami" que, pela classificação de Köppen é definido como tropical chuvoso com período seco definido, principalmente entre os meses de dezembro e março (Santos et al., 1982; Barbosa, 1997). A precipitação média anual varia entre 1.900 $2.000 \mathrm{~mm}$ (obs. pessoal), coincidindo com os dados apresentados por
Lameira \& Coimbra (1988) e Barbosa (1997) para as regiões próximas desta localidade.

Segundo BRASIL (1975), toda esta região é um forte contato entre três grandes grupos de solo: (a) podzólico vermelho-amarelo de textura média em solos concrecionários lateríticos, (b) latossolo vermelho-amarelo distrófico 
de textura média com areias quartzosas distróficas e (c) litólico distrófico sob afloramentos rochosos (serras). Nosso experimento foi montado em um grande bloco de latossolo vermelho-amarelo que, sob cobertura florestal original (Fdn), apresenta $\mathrm{pH}$ de 4,57 (ácido), 1,15\% de $\mathrm{C}_{\text {total }}$ e baixa concentração de nutrientes, principalmente fósforo assimilável (Barbosa \& Fearnside, sd).

\section{METODOLOGIA}

O método de montagem do experimento e os princípios básicos de coleta são os mesmos descritos em Fearnside et al. (1986) e Fearnside (1989) e, seguiram os seguintes critérios de seleção para as duas áreas de estudo (pasto e floresta): (a) topografia do terreno escolhido deveria possuir um declive de $20 \%$ para possibilitar comparações com outros estudos já desenvolvidos dentro do projeto original; (b) tanto a área de floresta primária quanto a de pastagem derivada de floresta deveriam pertencer ao mesmo tipo original de vegetação; (c) a espécie de gramínea implantada deveria ser representativa da região (no caso do Apiaú, a espécie amplamente adotada é a Brachiaria humidicola); (d) a pastagem deveria ser produtiva (iniciamos nossos estudos em um pasto com 4 anos de uso) e, (e) a distância entre os dois sistemas deveria ser pequena para que, em ambos os casos, as condições pluviométricas regionais fossem as mais semelhantes possivei's. Neste caso, a distância entre os dois sistemas foi de aproximadamente $1 \mathrm{~km}$. Em adição, (1) 0 gado não foi impedido de pisotear ou pastorear nas quadras da pastagem e (2) as queimadas para renovação do pasto seguiram normalmente o calendário do proprietário do loteamento agrícola. Da mesma forma que os passos anteriores, isto foi necessário para que a amostragem fosse a mais realistica possivel para o padrão regional.

O passo seguinte foi a instalação de 2 quadras coletoras de erosão em cada área escolhida, distanciadas de aproximadamente $50 \mathrm{~m}$. Cada quadra possuia um tamanho padrão de $1 \mathrm{~m} \mathrm{x}$ $10 \mathrm{~m}$, sendo montada seguindo o sentido do declive e, ladeada por lâminas de alumínio que serviam de bloqueio para possiveis entradas ou saídas de material erodido. Ao final de cada quadra instalamos calhas do tipo "Gerlach" (ver Gerlach, 1967; McGregor, 1980; Ploey \& Gabriels, 1980), para captar e conduzir o material erodido de dentro das quadras (água do escoamento superficial e sedimento bruto), para dois tambores receptores. Estes tambores possuiam capacidade aproximada de 200 litros cada e eram conectados às calhas através de canos (Figura 2). O objetivo era o de possibilitar a acomodação do material receptado por periodos longos.

O trabalho foi realizado entre agosto de 1988 e fevereiro de 1992 . O intervalo entre as coletas variava sempre em função do periodo 

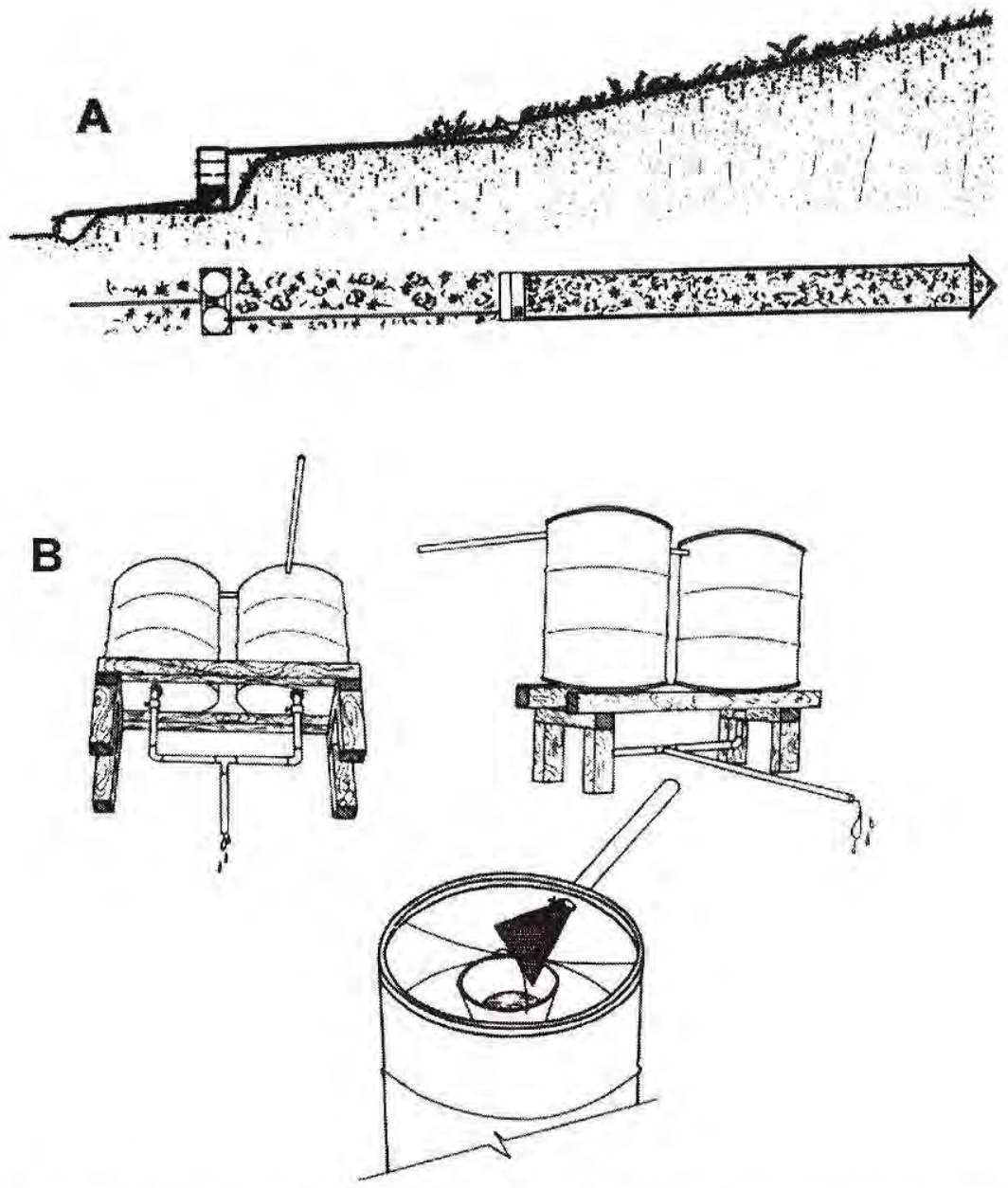

Figura 2. (A) Detalhes gerais de uma quadra de erosão no sistema de pastagem e (B) dos tambores de coleta de material erodido.

climático, alcançando um máximo de 34 dias (seco) e um mínimo de 3 dias (chuvoso). A coleta consistia em medir o volume de toda água ("runoff") contida nos tambores de coleta por uma fórmula matemática modificada do volume do cilindro (ver Fearnside et al., 1986). A modificação na fórmula do volume foi devido às reentrâncias que os tambores continham e que aumentavam a quantidade de água contida em cada um deles. Em seguida, era amostrado um litro do "runoff" (quantificação do material em suspensão), deixando-se vazar, aos poucos, o restante da água do tambor por uma válvula ao fundo. Isto permitia que, o material sedimentado no fundo do tambor fosse coletado e acondicionado em recipientes plásticos que em seguida eram levados ao laboratório. Em am- 
bos os casos, a amostra era seca em estufa à $105^{\circ} \mathrm{C}$ para determinação do peso seco do material perdido por suspensão e por arraste.

Para entender a relação de perda do solo entre o uso da terra e a precipitação, instalamos um pluviômetro em cada quadra da pastagem e, adaptamos 3 coletores de chuva para cada quadra da floresta com a mesma finalidade (6 no total). Estes últimos, consistiam em tambores de 200 litros cobertos com uma quadra plástica de $1 \mathrm{~m}^{2}$ para receptar a chuva. Portanto, aumentando a área de captação em um sistema em que a cobertura florestal favorece a grande variabilidade de queda d'água direta no solo. Isto foi uma tentativa de incorrer em menor erro sobre o total de água que efetivamente participou no processo de erosão do solo da floresta. $\mathrm{O}$ volume de água era medido da mesma forma que o volume dos tambores de coleta de erosão, obtendose uma medida em litros. $\mathrm{m}^{-2}$.

Com os resultados de escoamento superficial e sedimento total, por unidade de área e tempo, (a) aglutinamos 2-3 intervalos simples de coletas em intervalos compostos que representassem uma média aproximada de 30 dias $( \pm 5,2)$ para totalizar os 42 meses de observações $(n=42),(b)$ descartamos os intervalos onde os dados eram inexistentes, o que totalizou $n_{\text {pasto }}=37$ e $n_{\text {floresta }}=40$, (c) calculamos a média diária simples dentro de cada intervalo composto de tempo, (d) determinamos a diferença estatística (Teste-t) entre os dois sistemas para os três parâmetros envolvidos (erosão, escoamento e precipitação), (e) estimamos a média ponderada de perda de solo anual dando peso ao número de dias de cada intervalo composto para cada sistema e, (f) determinamos a média ponderada de cada período climático isoladamente (seca e chuva), aglutinando novamente os intervalos compostos em macro-períodos climáticos que variavam de 5-7 meses dependendo do término ou início das chuvas na região.

\section{RESULTADOS}

A erosão do solo provocada pelas chuvas na pastagem de $B$. humidicola $\mathrm{em}$ um declive de $20 \%\left(1.128 \mathrm{~kg} \cdot \mathrm{ha}^{-1}\right.$. ano $\left.{ }^{-1}\right)$ foi 7,5 vezes maior e estatísticamente diferente ( $\left.\mathrm{P}<0,001 ; \mathrm{t}_{0.05,1,36}\right)$, quando comparada com a da floresta primária (150 $\mathrm{kg} \cdot \mathrm{ha}^{-1} \cdot \mathrm{ano}^{-1}$ ) no mesmo período e nas mesmas condições climáticas e topográficas (Tab. 1). Decompondo estes valores em macro-periodos climáticos, as médias ponderadas foram as seguintes: 145 kg.ha ${ }^{-1}$.ano ${ }^{-1}$ (seco) e 1.729 kg.ha ${ }^{-1} \cdot$ ano $^{-1}$ (chuvoso) para a pastagem e, $30 \mathrm{~kg} \cdot \mathrm{ha}$ ${ }^{1}$. ano ${ }^{-1}$ (seco) e $338 \mathrm{~kg} \mathrm{ha}^{-1}$.ano ${ }^{-1}$ (chuvoso) para a floresta. $\mathrm{O}$ escoamento superficial da pastagem $\left(3,18 \times 10^{6}\right.$ l.ha ${ }^{-1}$.ano $\left.{ }^{-1}\right)$ foi 2,8 vezes superior ao da floresta $\left(1,13 \times 10^{6}\right.$ 1.ha- ${ }^{-1} \cdot$ ano $\left.^{-1}\right)$ e, da mesma forma que a erosão, estatisticamente diferente $(\mathrm{P}<$ 0,$\left.001 ; \mathrm{t}_{0.05,1,36}\right)$ (Fig. 3).

A média anual de precipitação na pastagem entre agosto/1988 e fevereiro/ 1992 foi de $2.109 \mathrm{~mm}$, enquanto que na floresta o indice foi de $1.538 \mathrm{~mm}$ anuais. Ambos os casos representam o volume de água que efetivamente atingiu o solo e que de alguma forma agiram no deslocamento de partículas do solo. A 
Tabela 1. Erosão do solo, escoamento superficial e precipitação pluviométrica nos sistemas de pastagem e floresta primária para o período de agosto/88 a fevereiro/92 na região do Apiaú, Roraima, Brasil.

Parâmetros Floresta Primária

Pastagem

(B. humidicola)

Precipitação
$\left(\mathrm{mm} \cdot \mathrm{mno}^{-1}\right)$

\section{Erosão}

(kg. ha- $\cdot$ ano $^{-1}$ )

\section{Escoamento Superficial}

$\left(10^{6}\right.$ I. ha $a^{-1} \cdot$ ano $\left.^{-1}\right)$

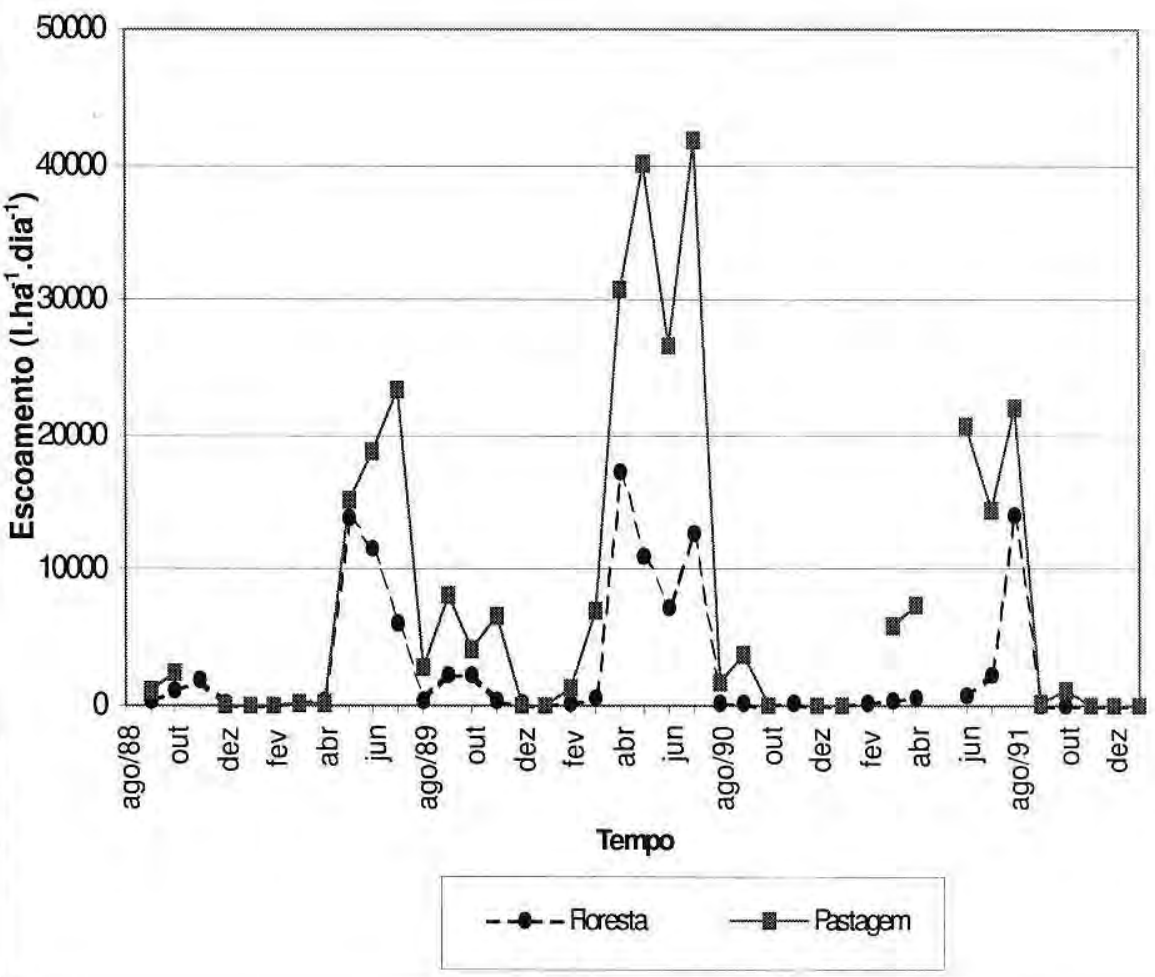

Figura 3. Comparação do escoamento superficial $\left(10^{6} 1 \cdot \mathrm{ha}^{-1} \cdot \mathrm{dia}^{-1}\right)$ entre os sistemas de floresta e pastagem para o periodo de agosto/88 a fevereiro/92 na região do Apiaú, Roraima, Brasil. 
porcentagem de escoamento superficial em relação à precipitação média anual durante todo o período de coleta foi de $15,1 \%$ para a pastagem e $7,4 \%$ na floresta.

\section{DISCUSSÃO}

A erosão na pastagem foi sempre maior do que na floresta tanto na média anual ponderada como nas médias decompostas obtidas nos diferentes periodos climáticos (seca e chuva). Estes resultados, apenas diferem dos valores encontrados por Fearnside et al. (1986) em Manaus (AM) e Fearnside (1989) em Ouro Preto d'Oeste (RO), quanto à magnitude dos números, pois a grande diferença obtida entre os dados de floresta e pasto foi mantida (Tab. 2).

Outra investigação da mesma natureza foi realizada em Roraima, na Estação Ecológica de Maracá por um período de apenas 2 meses (julhosetembro/1987) no pico do periodo chuvoso através de calhas tipo "Gerlach" em três diferentes declives. Os resultados médios relatados por Nortcliff et al. (1989), Ross et al. (1990) e Ross (1992) indicam diferença estatísticamente significativa em áreas recentemente desmatadas (1.140 kg.ha $\left.{ }^{-1} \cdot \mathrm{mes}^{-1}\right)$ quando comparadas com áreas parcialmente desmatadas (475 kg.ha- $\left.\cdot \mathrm{mes}^{-1}\right)$ e floresta virgem $\left(270 \mathrm{~kg} \cdot \mathrm{ha}^{-1} \cdot \mathrm{mes}^{-1}\right)$. Embora sem possiblidade de comparação devido ao curto espaço de tempo e ao período em que foram realizadas as coletas de dados (pico da chuva), estes resultados, da mesma que os da região do Apiaú, sugerem forte diferença entre diferentes usos da terra em Roraima.

Estudos de erosão na Amazônia brasileira são praticamente inexistentes. Além dos trabalhos listados na Tabela 2, somam-se o de Smith (1976) e o de Fearnside (1980), que realizaram medidas de erosão pelo método das estacas na Rodovia Transamazônica, próximo de Altamira/PA. Ambos encontraram fortes perdas de solo em diferentes culturas anuais. Entretanto, embora este método proporcione observar as diferenças entre agrossistemas pelo rebaixamento da superfície do solo, ele descarta o efeito da compactação do solo. Contudo, a compactação é um fator que pode rapidamente incrementar a erosão devido ao aumento da densidade nos solos alterados para agricultura ou pastagens (Eden et al., 1991a; 1991b).

Em uma outra investigação realizada em 10 bacias de sedimentação na Guiana Francesa, Fritsch (1981) estimou uma erosão média sob florestas primárias como sendo de 642 kg.ha- ${ }^{-1}$ em 1979, sob uma precipitação de $3.382 \mathrm{~mm}$. Este número é próximo aos $410 \mathrm{~kg} \cdot \mathrm{ha}^{-1} \cdot \mathrm{ano}^{-1}$ (3.600 mm) estimado por Hoepffner \& Rodier (1976) em uma bacia hidrográfica de 32 ha em Crique Grégorie, também na Guiana Francesa. Estes valores não fogem ao padrão apresentado na Tabela 2 , mesmo considerando a influência dos altos indices pluviométricos e a impossibilidade de comparações com sistemas adjacentes transformados. 
Tabela 2. Erosão, escoamento superficial e porcentagem do escoamento em relação a precipitação, em algumas localidades amazônicas.

\begin{tabular}{|c|c|c|c|c|c|}
\hline Uso da Terra & $\begin{array}{c}\text { Erosăo } \\
\left(\mathrm{Kg}^{-h^{-1}} \text {, ano-1) }\right.\end{array}$ & $\begin{array}{c}\text { Escoamento } \\
\text { Superficial } \\
\left(10^{6} 1 . \text { ha }^{-1} \text {.ano }\right. \\
\end{array}$ & $\begin{array}{c}\text { Escoamento/ } \\
\text { Prescipitação } \\
(\%)\end{array}$ & Localidade & Fonte \\
\hline $\begin{array}{l}\text { Pastagem } \\
\text { (B. humidicola) }\end{array}$ & 1.703 & 2,32 & - & Manaus (AM) & $\begin{array}{l}\text { Fearnside } \\
\text { et al. (1986) }\end{array}$ \\
\hline Floresta Primária & 158 & 0,27 & - & & \\
\hline $\begin{array}{l}\text { Pasto Limpo } \\
\text { (P. maximum) }\end{array}$ & 3.556 & 9,87 & 49,8 & $\begin{array}{l}\text { Ouro Preto } \\
\text { d'Oeste (RO) }\end{array}$ & Fearnside (1989) \\
\hline $\begin{array}{l}\text { Pasto Sujo } \\
\text { (P. maximum) }\end{array}$ & 664 & 5,03 & 25,7 & & \\
\hline $\begin{array}{l}\text { Floresta } \\
\text { Primária }\end{array}$ & 330 & 0,37 & 2,2 & & \\
\hline $\begin{array}{l}\text { Floresta } \\
\text { Primária }\end{array}$ & 410 & - & - & $\begin{array}{l}\text { Crique } \\
\text { Gregorie (G. } \\
\text { Francesa) }\end{array}$ & $\begin{array}{l}\text { Hoepffner \& Rodier } \\
\text { (1976) }\end{array}$ \\
\hline $\begin{array}{l}\text { Floresta } \\
\text { Primária }\end{array}$ & 642 & - & - & G. Francesa & Fritsch (1981) \\
\hline $\begin{array}{l}\text { Recentemente } \\
\text { Desmatado (1) }\end{array}$ & 1.140 & - & - & $\begin{array}{l}\text { liha de } \\
\text { Maracá (RR) }\end{array}$ & $\begin{array}{l}\text { Nortcliff et al. } \\
\text { (1989), } \\
\text { Ross et al. (1990) } \\
\text { e Ross } \\
(1992)\end{array}$ \\
\hline $\begin{array}{l}\text { Parcialmente } \\
\text { Desmatado }\end{array}$ & 475 & - & - & & \\
\hline $\begin{array}{l}\text { Floresta } \\
\text { Primária }\end{array}$ & 270 & - & - & & \\
\hline $\begin{array}{l}\text { Pastagem } \\
\text { (B. humidicola) }\end{array}$ & 1.128 & 3,18 & 15,1 & Apiaú (RR) & $\begin{array}{l}\text { Este } \\
\text { Estudo }\end{array}$ \\
\hline $\begin{array}{l}\text { Floresta } \\
\text { Primária }\end{array}$ & 150 & 1,13 & 7,4 & & \\
\hline
\end{tabular}

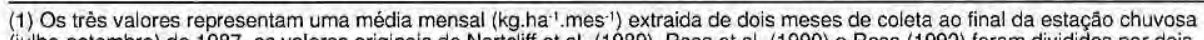
(julho-setembro) de 1987. os valores originais de Nortcliff et al. (1989), Ross et al. (1990) e Ross (1992) foram divididos por dois para obtençăo da média citada.

A retirada da cobertura florestal para introdução de pastagens, deixa o solo exposto diretamente aos fortes raios solares, ao pisoteio intenso do gado e a ação direta das chuvas tropicais. Elwell \& Stocking (1976) determinaram que com a perda de $70 \%$ da cobertura original, a erosão se elevaria drasticamente devido ao maior impacto da chuva sobre o solo. Nosso estudo detectou uma diferença de $571 \mathrm{~mm}(37 \%)$ de chuva entre a pastagem e a floresta. O maior volume de água e a maior força de impacto da chuva sobre o solo da pastagem são consequência direta da falta da cobertura florestal natural. Devido a estes fatores a chuva que cai se transforma em grande parte em escoamento superficial que carreia maior volume de solo para outros reservatórios, principalmente para as 
baixadas e leitos dos rios. Isto pode ser constatado pela diferença entre as medidas de escoamento da pastagem $\left(3,18 \times 10^{6} 1\right.$ ha $^{-1} \cdot$ ano $\left.^{-1}\right)$ e da floresta $\left(1,13 \times 10^{6} 1\right.$ ha $^{-1} \cdot$ ano $\left.^{-1}\right) \mathrm{e}$, pela relação entre escoamento superficial e precipitação que efetivamente atingiu o solo. Na floresta, esta relação foi de apenas $7,4 \%$, enquanto que na pastagem este valor foi duas vezes superior $(15,1 \%)$. Ambas as análises indicam o forte impacto que a transformação de grandes áreas de floresta amazônica poderia ter sobre o ciclo hidrológico regional.

As queimadas, para renovação e limpeza das pastagens antes do periodo chuvoso, também possuem um efeito devastador pois eliminam a única proteção que o solo ainda possui (Eden et al., 1991b; Barbosa \& Fearnside, 1996). Por exemplo, no local onde foi montado o experimento, o fogo foi ateado no capim ao final da estação seca de 1991. As primeiras chuvas elevaram a média diária de perda de solo de 1,9$3,7 \mathrm{~kg} \cdot \mathrm{ha}^{-1} \cdot \mathrm{dia}^{-1}$ obtida nos periodos chuvosos anteriores, para $8,6 \mathrm{~kg} \cdot \mathrm{ha}^{-1} \cdot \mathrm{dia}^{-1}$ até que o capim conseguisse se recompor. No mesmo período, a floresta não ultrapassou os $0,7 \mathrm{~kg} \mathrm{ha}^{-1} \cdot \mathrm{dia}^{-1}$ (Fig. 4). Esta diferença pode ter um efeito drástico na exportação de carbono estocado na matéria orgânica dos solos tropicais para reservatórios marinhos influenciando a distribuição de carbono em diferentes compartimentos (Fearnside et al., 1986).

\section{CONCLUSÃO}

A taxa de erosão na pastagem $\left(1.128 \mathrm{~kg} \cdot \mathrm{ha}^{-1} \cdot \mathrm{ano}^{-1}\right)$ foi superior por um fator de 7,5 à da floresta adjacente (150 $\left.\mathrm{kg} \cdot \mathrm{ha}^{-1} \cdot \mathrm{ano}^{-1}\right)$. Isto causa degradação sucessiva na fertilidade do solo e sugere que pastagens derivadas de florestas na Amazônia são sistemas não-sustentáveis de uso da terra para a região. Os resultados também sugerem que as políticas governamentais atuais implicam em um grande custo ambiental, pois continuam levando grandes áreas de floresta amazônica à conversão em pastagens.

\section{AGRADECIMENTOS}

O Governo de Roraima financionou parte deste trabalho através do Convênio INPA/GTFR $\mathrm{n}^{\circ}$ $072 / 85$. Paulo Maurício L. de Alencastro Graça, Niwton Leal Filho, José Lucas Filho e Geovani Rocha da Silva colaboraram na escolha dos locais e/ou na montagem das quadras de coleta de erosão. Regina Martoni Mansur Corrêa da Costa e Ezio de Jesus Gomes de Lucas colaboraram no trabalho de coleta de campo. Agradecemos dois referees anônimos pelos comentários.

\section{Bibliografia citada}

Barbosa, R.I. 1991. Erosão do solo na Colônia do Apiaú, Roraima, Brasil - Dados Preliminares. Bol. Mus. Integ. Roraima, I(2): 22-40.

Barbosa, R.I. 1993. Ocupação humana em Roraima. II. Uma revisão do equívoco da recente política de desenvolvimento e o crescimento desordenado. Bol. Mus. Par. Emilio Goeldi (Série Antrop.), 9(2): $177-$ 197.

Barbosa, R.I. 1997. Distribuição das chuvas em 


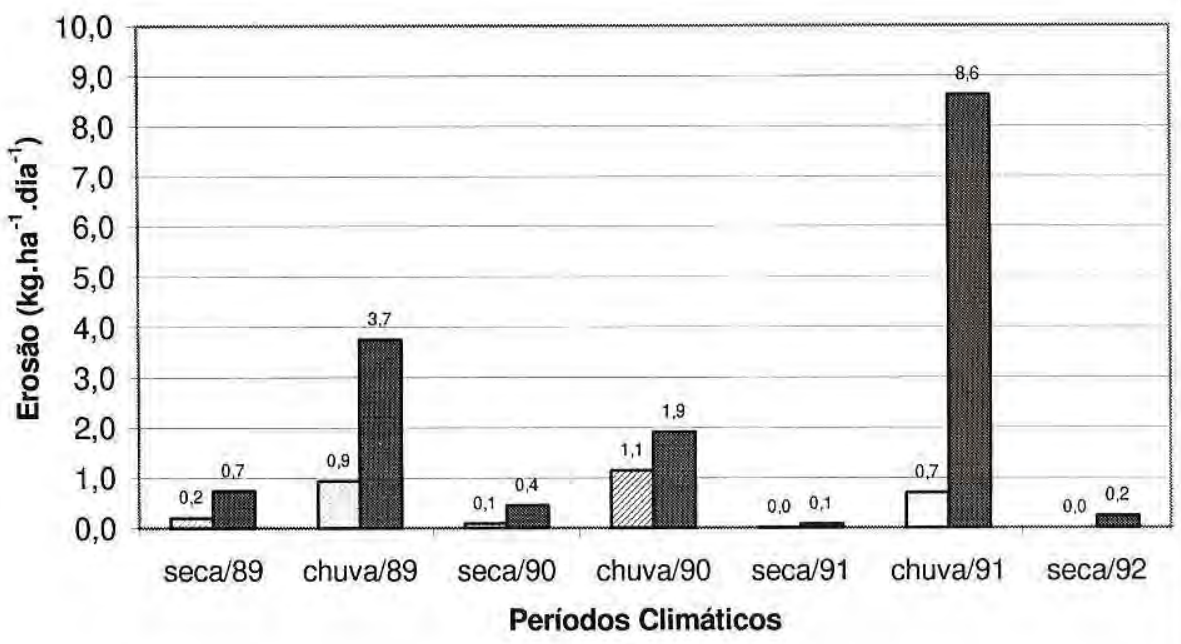

口Floresta 맘 Pastagem

Figura 4. Diferença entre as médias de erosão $\left(\mathrm{kg} \cdot \mathrm{ha}^{-1} \cdot \mathrm{dia}^{-1}\right)$ obtidas dentro dos períodos de seca e de chuva entre agosto/88 e fevereiro/92 na região do Apiaú, Roraima, Brasil.

Roraima. In: Barbosa, R. I.; Ferreira, E.; Castellón, E. (eds.), Homem, Ambiente e Ecologia no Estado de Roraima. INPA/ Manaus, p. 325-335.

Barbosa, R.I,; Fearnside, P.M. 1996a. Carbon and nutrient flows in an Amazonian forest: fine litter production and composition at Apiaú, Roraima, Brazil. Tropical Ecology, 37(1): 115-125.

Barbosa, R.I.; Fearnside, P.M. 1996b. Pasture burning in Amazonia: Dynamics of residual biomass and storage and release of above ground carbon. Journal of Geophysical Research, 101(D20): 25847 25857.

Barbosa, R.I.; Fearnside, P.M. sd. Queima de pastagens na Amazônia: mudanças de curto prazo no estoque de carbono $e$ nutrientes do solo (Manuscrito em fase de redação).

Barbosa, R.I.; Fearnside, P.M. 1999. Incêndios na Amazônia brasileira: estimativa da emissão de gases do efeito estufa pela queima de diferentes ecossistemas de
Roraima na passagem do Evento "El Niño" (1997/98). Acta Amazonica, 29(4): 513-534.

BRASIL. 1975. Projeto RADAMBRASIL - Volume 8. Ministério da Minas e Energia/ Departamento de Recursos Naturais. Rio de Janeiro. 428p,

Braun, W.A.G. 1962 (1961). Contribuição ao estudo da erosão no Brasil e seu controle. Separata da Revista Brasileira de Geografia (out-dez/1961), no 4. 54p.

Brown, L.R.; Wolf, E.C. 1984. Soil erosion: quiet crisis in the world economy. Worldwatch Paper Series, 60. 49p.

Eden, M.J.; McGregor, D.F.M.; Vieira, N.A.Q. 1991a. Soil physical and chemical properties of cultived pasture on forest land, Roraima, Brazil. Acta Amazonica, 21(único): 375-390.

Eden, M.J.; Furley, P.A.; McGregor, D.F.M.; Milliken, W.; Ratter, J.A. 1991b. Effect of forest clearance and burning on soil properties in Northern Roraima, Brazil. Forest Ecology and Management, 38: 283-290. 
Elwell, H.A.; Stocking, M.A. 1976. Vegetative cover to estimate soil erosion hazard in Rhodesia. Geoderma, 15: 61-70.

Fearnside, P.M. 1980. A previsão de perdas de terra através de erosão de solo sob vários usos de terra na área de colonização da Rodovia Transamazônica. Acta Amazonica, 10(3): 505-511.

Fearnside, P.M. 1986. Human carrying capacity of the Brazilian Rainforest. Columbia University Press, New York, EUA. 293 p.

Fearnside, P.M. 1989. A Ocupação Humana de Rondônia - Impactos, Limites e Planejamento. Programa Polonoroeste/ SCT-PR/CNPq. Relatório de Pesquisa $\mathrm{n}^{\circ}$ 5. $76 \mathrm{p}$.

Fearnside, P.M.; Barbosa, R.I. 1998. Soil carbon changes from conversion of forest to pasture in Brazilian Amazonia. Forest Ecology and Management, 108: 147-166

Fearnside, P.M.; Leal Filho, N.; Chaves, R.G.; Moreira, F.F.; Keller, M.M.; Custódio, R.A. 1986. Soil erosion in the Brazilian Amazon: measurement methods and preliminary results. Instituto Nacional de Pesquisas da Amazônia. Manaus. 34 p. (Manuscrito).

Forsberg, B.; Godoy, J.M.; Victoria, R. 1989. Development and erosion in the Brazilian Amazon: A geochronological case study. Geojournal, 19(4): 399, 402-405.

Fritsch, J.M. 1981. Ecoulement et érosion sur les bassins versants ECEREX en 1979. L'écosysteme Forestier Guyanais - Etude et Mise en Valeur. Bulletin de Liaison du Groupe de Travail $\mathrm{n}^{\circ} 4$ (CTFT/INRA/ MUSEUM/ORSTOM). p. 23-44.

Gerlach, T. 1967. Hillslope troughs for measuring sediment movement. Revue de Geomorphologie Dynamique, 17: 173.

Hoepffner, M.; Rodier, J. 1976. Atlas des Departements D'Outremer / La Guyane (Planche 9). Hydrologie, p. 2.

INPE. 2000. Monitoramento da Floresta Amazônica Brasileira por Satélite 19981999. Instituto Nacional de Pesquisas Espaciais (INPE), abril de 2000. 22p.

Lal, R. 1977. Review of soil erosion research in Latin America. In: Greenland, D.J.; Lal, R. (org.). Soil Conservation and Management in the Humid Tropics. J. Wiley \& Sons, New York. p. 231-240.

Lameira, O.A.; Coimbra, J.M. 1988. Levantamento e distribuição da precipitação em Roraima. EMBRAPAUEPAT/BV-RR. Pesquisa em Andamento $n^{\circ}$ 12. Boa Vista. 5p.

McGregor, D.F.M. 1980. An investigation of soil erosion in the Colombian rainforest zone. Catena 7(4): 265-273.

Mougeot, L.; Léna, P. 1994. Forest clearance and agricultural strategies in Northern Roraima. In: Furley,P. A. (ed.) The Forest Frontier - Settlement and Change in Brazilian Roraima. Routledge. New York. p. 111-152.

Myers, N. 1988. Natural resource systems and human exploitation systems: physiobiotic and ecological linkages. Environmental Department Working Paper, 12 (World Bank). 61p.

Nortcliff, S.; Ross, S.M.; Thornes, J.B. 1989. Soil moisture, runoff and sediment yield from differentially cleared tropical rainforest plots. In: J.B. Thornes (ed.), Vegetation and Erosion. John Wiley, Chichester. p. 419-436.

Pimentel, D.; Harvey, C.; Resosudarmo, P.; Sinclair, K.; Kurz, D.; McNair, M.; Crist, S.; Shpritz, L.; Fitton, L.; Saffouri, R.; Blair, R. 1995. Environmental and economic costs of soil erosion and conservation benefits. Science (24.02.1995), 267: 1117-1123.

Ploey, J.; Gabriels, D. 1980. Measuring soil loss and experimental studies. In: Kirkby, M.K.; Morgan, R.P.C. (comp.) Soil Erosion. John Wiley \& Sons. New York. p. 63-108.

Ross,S.M.; Thornes,J.B.; Nortcliff,S. 1990. Soil hydrology, nutrient and erosional response to the clearance of terra firme forest, Maracá Island, Roraima, Northern Brazil. Geographical Journal, 156: 267 282.

Ross, S.M. 1992. Soil and litter nutrient losses in forest clearings close to a forest savanna 
boundary on Maracá Island, Roraima, Brazil. In: Furley, P. A.; Proctor, J.; Ratter, J.A. (eds.), Nature and Dynamics of Forest-Savanna Boundaries, Chapman \& Hall, London. p. 119-143.

Santos, R.D.; Gama, J.N.R.F.; Soares, A.F. 1982. Levantamento de reconhecimento de baixa intensidade dos solos e avaliação da aptidão agrícola das terras do projeto de colonização Apiaú, Território Federal de Roraima. Boletim de Pesquisa $n^{\circ} 14$. Empresa Brasileira de Pesquisa Agropecuária/Serviço Nacional de Levantamento e Conservação de Solos (EMBRAPA/SNLCS), 175p.

Silveira, I.M; Gatti, M. 1988. Notas sobre a ocupação de Roraima, migração e colonização, Bol. Mus. Par. Em. Goeldi, $4(1): 43-64$.

Smith, N.J.H. 1976. Transamazon Highway: $A$ cultural-ecological analysis of settlement in the humid tropics. $\mathrm{PhD}$ thesis in Geography, University of California, Berkeley. $372 \mathrm{p}$. 